\title{
Survivorship and reproduction of translocated Tipton kangaroo rats in the San Joaquin Valley, California
}

\author{
David J. Germano선 ${ }^{1}$ Lawrence R. Saslaw ${ }^{2}$, Paul T. Smith ${ }^{1}$, Brian L. Cypher ${ }^{3}$ \\ ${ }^{1}$ Department of Biology, California State University, Bakersfield, California 93311-1022, USA \\ ${ }^{2}$ US Bureau of Land Management, 3801 Pegasus Drive, Bakersfield, California 93308, USA \\ ${ }^{3}$ Endangered Species Recovery Program, PO Box 9622, Bakersfield, California 93389-9622, USA
}

\begin{abstract}
A potential means of mitigating the impact that development has on animals is to move affected individuals to new areas where development will not occur or to release individuals back to a site after activities have ceased. In the case of translocation, the desired outcome is that the majority of the translocated individuals will survive and reproduce in a new, uninhabited and protected site, such that there is no net loss of endangered animals. Because of project displacement, we moved 144 Tipton kangaroo rats Dipodomys nitratoides nitratoides, a state and federally listed endangered species, to a preserve north of Bakersfield, California, USA, in December 2006 that had no Tipton kangaroo rats, but was known habitat. To help determine short-term survivorship, we radio-tracked 22 individuals for $30 \mathrm{~d}$ post-release. We placed 14 radio-collared kangaroo rats in cages with artificial burrows (soft release) on site and 8 radio-collared individuals in artificial burrows without cages (hard release). We placed all other kangaroo rats in artificial burrows with $(n=86)$ or without $(n=36)$ cages. The percentage survivorship of radio-tagged kangaroo rats that were soft-released $(58.3 \%)$ was greater than that of radio-tagged animals hard-released $(37.5 \%)$, but the differences were not significant. Trapping over 3 yr showed a small, but persistent, population of Tipton kangaroo rats. We caught 38 new Tipton kangaroo rats in these 3 yr. Based on an AMOVA of genotypic data from 2 microsatellite loci of Tipton kangaroo rats translocated to the site, unmarked young caught on site are consistent with being offspring of the translocated animals. Future research should address the value of caging kangaroo rats on sites prior to release, the relative merit of short-term removal of competing species, and appropriate habitat management strategies.
\end{abstract}

KEY WORDS: Conservation - Tipton kangaroo rat · Dipodomys nitratoides · Endangered species · Translocation $\cdot$ Population abundance Resale or republication not permitted without written consent of the publisher

\section{INTRODUCTION}

The Tipton kangaroo rat Dipodomys nitratoides nitratoides is 1 of 3 taxa of kangaroo rats that are state and federally listed as endangered in the San Joaquin Valley of California, USA. Tipton kangaroo rats occur on only 3 to $4 \%$ of their former range (Williams \& Germano 1992), and their numbers continue to de- cline (Uptain et al. 1999). Additionally, like other rodents in the valley, Tipton kangaroo rats experienced severe declines in population size in the 1990s, likely due to unusually high amounts of rain that led to dense herbaceous growth and, consequentially, suboptimal habitat conditions throughout their range (Single et al. 1996). Disease may have also contributed to these declines (Single et al. 1996). Despite 
their protected status, developmental activities continue to be permitted in their fragmented habitat.

A potential means of mitigating the impact that development has on Tipton kangaroo rats is to move affected individuals to new areas where development will not occur or to release individuals back to a site after activities have ceased. In the case of translocation, the desired outcome is that the majority of the translocated individuals will survive and reproduce at a new, uninhabited and protected site, such that there is no net loss of endangered animals (Griffith et al. 1989). As an example, the translocation of the Perdido Key beach mouse Peromyscus polionotus trissyllepsis in Alabama successfully reestablished this species in a part of its range where it had been extirpated (Holler et al. 1989). However, the eventual outcome of translocating animals is often left undetermined, and in the few cases where individuals have been monitored, translocation usually was not successful (Fischer \& Lindenmayer 2000). This is the case with Tipton kangaroo rats. Agencies responsible for the protection of this species allowed the reintroduction and translocation of Tipton kangaroo rats several times in the 1990 s as a means to mitigate the effects of development (Germano 2001). Assessment of the outcome of translocating this species has not been done in the majority of cases.

Germano (2001) reported on the project-associated reintroductions that he made with this species, as well as 5 cases in which individuals of this species were translocated to other parts of its range because of development. These efforts included placing Tipton kangaroo rats into artificial burrows and trapping at translocation sites several times afterwards, in some cases up to 6 mo post-release, to assess success. Outcomes were equivocal in most instances because trapping may not have detected some individuals that may have survived. An additional study followed the fate of 4 Tipton kangaroo rats and 7 Heermann's kangaroo rats Dipodomys heermanni using radiocollared animals placed into artificial burrows (Germano 2010). All 4 Tipton kangaroo rats were dead within $5 \mathrm{~d}$ of release. Of the 7 Heermann's kangaroo rats that were translocated, 3 were dead within $2 \mathrm{~d}$ of release, 1 was dead in $4 \mathrm{~d}$, and 1 was dead in $22 \mathrm{~d}$. Only 1 Heermann's kangaroo rat survived for the length of the study (45 d) and had its radio-collar removed. Loss of animals was thought to be either by predation (on Tipton kangaroo rats) or by predation and fighting with resident kangaroo rats (for Heermann's kangaroo rats).

All these translocations were essentially hardreleases to sites, although artificial burrows were made for individual kangaroo rats. Soft-release using some method of holding the animal in a confined area to allow time for the individual to acclimate to a new site and to protect the animal from predation may improve survivorship of translocated animals. Softrelease has been successful for some avian species (Gatti 1981, Ellis et al. 2000, Wanless et al. 2002, Mitchell et al. 2011) and small mammals (Holler et al. 1989, Bright \& Morris 1994), and, when combined with keeping social grouping intact, was successful with the Stephen's kangaroo rat Dipodomys stephensi in southern California, USA (Shier \& Swaisgood 2012). However, in other reintroduction experiments, softreleases have not improved survival, site fidelity, or body condition (Hardman \& Moro 2006).

Because a population of Tipton kangaroo rats was to be displaced from their resident habitat by a permitted development near Lamont, California, we translocated a large number of animals to a California Department of Fish and Game preserve that formerly supported this species. All of the translocated kangaroo rats were placed in artificial burrows, some of which were covered with wire-mesh cages. We believed that cages would increase survivorship. Some translocated kangaroo rats that were hard- and soft-released were fitted with radio-collars so their exact fate could be determined. Additionally, we followed the population of Tipton kangaroo rats for $3 \mathrm{yr}$ and compared the genetic signature of unmarked kangaroo rats caught at the site to that of the translocated kangaroo rats to determine if offspring were being produced.

\section{MATERIALS AND METHODS}

\section{Study area}

We translocated kangaroo rats Dipodomys nitratoides nitratoides from a site southeast of Bakersfield, in Kern County, to the Allensworth Ecological Reserve in southern Tulare County, approximately $60 \mathrm{~km}$ north of Bakersfield, California, USA. Allensworth consists of a patchwork of parcels that total 2142 ha that are owned and managed by the California Department of Fish and Game. At Allensworth, there are some continuous large parcels (>500 ha) as well as some non-continuous smaller parcels that are intermixed with conservation, agricultural, and grazing lands in private ownership (California Department of Fish and Game unpubl. report). Parcels on the reserve are both fenced and unfenced; thus, trespass grazing by the cattle of adjacent landowners 
occurred on some parcels within the reserve during the study.

Vegetation communities at Allensworth are classified as Valley Sink Scrub, Valley Saltbush Scrub, and California Annual Grassland (Holland 1986). These communities consist of non-native grasses and forbs mixed with common Atriplex polycarpa and spiny A. spinifera desert saltbush, iodine bush Allenrolfea occidentalis, and bush seepweed Suaeda moquinii. Soils at Allensworth are primarily sandy to fineloamy and are typically highly alkali, with moderate to poor drainage (Natural Resource Conservation Service). The vegetation community at the donor site, near Lamont, was similar to Allensworth, although there were open playas not found at the recipient site.

Allensworth is considered one of the core protected areas for Dipodomys nitratoides nitratoides (US Fish and Wildlife Service 1998). Yet, since 1994, relatively few $D$. n. nitratoides, as well as other endangered species, such as the blunt-nosed leopard lizard Gambelia sila and San Joaquin kit fox Vulpes macroitis mutica, have been detected on the reserve (M. Potter, California Department of Fish and Game, pers. comm.). A relatively cool and wet winter in 1994/ 1995 contributed to declines of kangaroo rats at several sites throughout the region, and surface flooding and dense vegetative growth at Allensworth likely had a negative effect on $D$. n. nitratoides populations (Single et al. 1996).

\section{Translocation}

In December 2006 we translocated 144 Tipton kangaroo rats from the Lamont water-spreading basin site in Kern County to the Allensworth Ecological Reserve in Tulare County, California, about $85 \mathrm{~km}$ to the north of the Lamont site. Trapping (795 trap nights) occurred at the translocation site 3 mo prior to our translocating animals, and only 1 Heermann's kangaroo rat and 1 San Joaquin pocket mouse Perognathus i. inornatus were caught (California Department of Fish and Game unpubl. data). We did not see any active kangaroo rat burrows (fresh dirt, scat, tracks, tail drags) during an inspection of the site either. In addition, the rest of Allensworth Reserve had a dense cover of grass, and there were no signs of kangaroo rats throughout the rest of the reserve. Adjacent land was irrigated agriculture.

Tipton kangaroo rats were trapped by project consultants at the donor site over several nights in late November and early December of 2006 (8464 trap nights; M. Wolfe, pers. comm.). Animals were transferred to us for marking and measuring each morning after a night of trapping. We marked all kangaroo rats by inserting a passive integrated transponder (PIT) tag under the skin (Williams et al. 1997). We also took an ear clip (stored in 99\% ethanol) from each kangaroo rat for future genetic analysis and as a reference to which we could compare any unmarked Tipton kangaroo rats caught at a later date. A first round of trapping at the donor site captured 70 Tipton kangaroo rats (42 male, 28 female) that we processed between 28 November and 9 December 2006. One animal died during handling. A second group of 75 kangaroo rats (42 males, 33 females) was captured a week later, and we processed them from 13 to 14 December. We kept both groups of Tipton kangaroo rats for several days in $19 \mathrm{l}$ plastic buckets with wiremesh tops before placing them at the translocation site. Buckets contained about $3 \mathrm{~cm}$ of sand, and we included a tin can to act as a shelter, and bird seed for food. Buckets were kept in the lead author's home office.

We released the 2 groups of kangaroo rats on opposite sides of a shallow, dry canal that bisected a portion of the Allensworth Ecological Reserve (Fig. 1). The canal rarely contained water, and we found later that kangaroo rats could move across it. On the south side, we placed the first group of 69 kangaroo rats into artificial burrows from 3 to 10 December 2006; 30 burrows were covered by wire-mesh cages, and 39 were not. We made artificial burrows using a soil auger digging into the ground at about a $30^{\circ}$ angle to a length of about $1 \mathrm{~m}$. We used a $25 \mathrm{~mm}$ diameter auger for holes inside cages (close to natural size; Germano \& Rhodehamel 1995) and $100 \mathrm{~mm}$ diameter auger for holes outside cages. The larger holes allowed us to force kangaroo rats into the artificial burrow so we could plug the entrance until nightfall. The depths of the artificial burrows were similar to the depth below ground for actual kangaroo rat burrows in the San Joaquin Valley (Germano \& Rhodehamel 1995). We provisioned artificial burrows with about 0.11 of parakeet-mix seeds and a paper towel for use in thermoregulation, and we spaced burrows at 10 to $15 \mathrm{~m}$ intervals to avoid aggressive interaction among animals. We used $6.4 \mathrm{~mm}$ (1/4 inch) hardware cloth to construct cages; each was about $90 \times 60 \mathrm{~cm}$ and was closed on the top and open on the bottom. After a burrow was dug, we dug trenches around the burrow to bury the sides of the cage to about $20 \mathrm{~cm}$ deep to discourage animals from digging out. We left a corner of the top of the cage open until we put a kangaroo rat into the finished cage. 


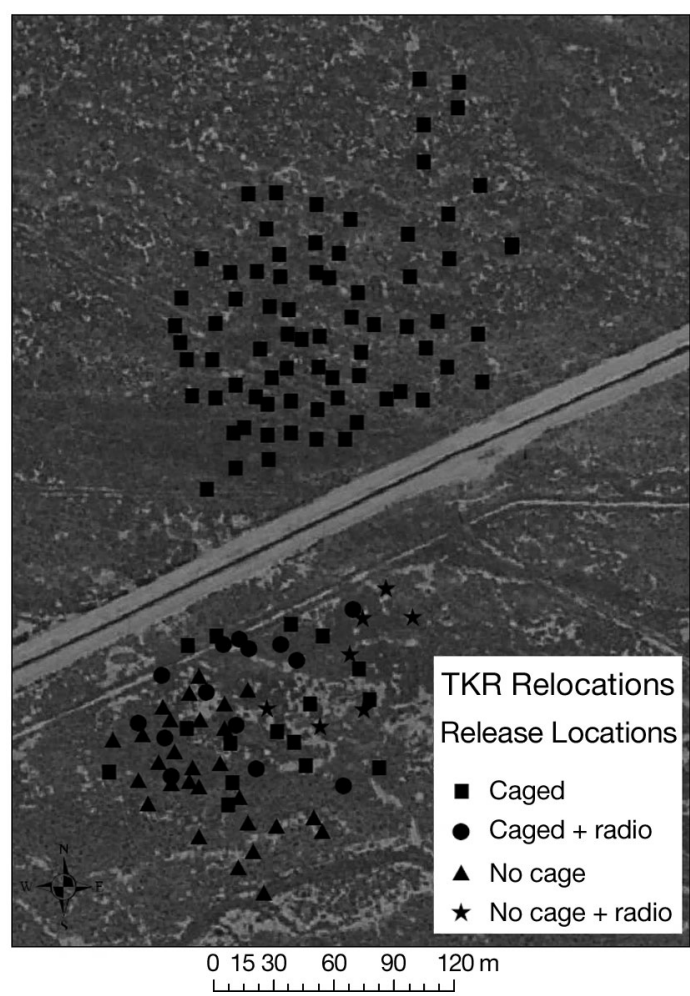

Fig. 1. Dipodomys nitratoides nitratoides. Initial location of the 69 (south site-lower area) and 75 (north site-upper area) Tipton kangaroo rats (TKR) translocated to Allensworth Ecological Reserve in December 2006. Animals were soft-released (caged) or hard-released (no cage), with or without a radio-collar. The site was divided by a shallow $(2 \mathrm{~m})$, narrow $(3 \mathrm{~m})$ dirt canal that intermittently carried water and $5 \mathrm{~m}$ wide dirt roads bordering the canal (light line in the middle of photograph)

For hard-released animals, we placed kangaroo rats into artificial burrows and plugged the entrance to the burrow with waded paper towels until evening when we unplugged the burrow to allow the animal to exit. We attempted to do this with kangaroo rats in cages, but the diameter of burrows were smaller $(25 \mathrm{~mm})$ than those we made outside of cages $(100 \mathrm{~mm})$, and we could not keep kangaroo rats restrained inside the burrow long enough to plug the burrow. Although nighttime temperatures were $<0^{\circ} \mathrm{C}$, all kangaroo rats voluntarily entered artificial burrows based on inspections the following mornings.

We placed all 75 kangaroo rats on the north side into caged artificial burrows from 15 to 21 December. Animals on both sides were re-provisioned with seeds 3 to 4 times during the $30 \mathrm{~d}$ cages remained in place. We removed cages from the south side on 6 January 2007 and on the north side on 21 January.

\section{Radio telemetry}

To improve the likelihood of determining the exact fate of some of the translocated kangaroo rats, we put radio-collars on 14 soft-released individuals and on 7 hard-released kangaroo rats. One of the hard-released rats was killed by a predator within $1 \mathrm{~d}$ of release; its radio collar was recovered and transferred to an 8th hard-release animal. We custom fitted $2.2 \mathrm{~g}$ radio-transmitters (Model BD-2, Holohil Systems) attached to a beaded chain around the neck of kangaroo rats (modified after Harker et al. 1999). Tipton kangaroo rats weighed 30 to $40 \mathrm{~g}$ when they were collared, and the radio-collars represented 5.5 to $7.3 \%$ of body mass. We kept these animals in $19 \mathrm{l}$ buckets for 24 to $36 \mathrm{~h}$ to assure that the collars fit well and that the animals had adjusted to wearing a collar.

We tracked all radio-collared kangaroo rats daily for $7 \mathrm{~d}$ post-release and then 3 times a week after that for $30 \mathrm{~d}$ or until they were found dead or went missing. For those kangaroo rats inside cages, we tracked them for $30 \mathrm{~d}$ once cages were removed or after they dug out of the cages. We judged a radio-collared kangaroo rat to have been successfully established at the site if it survived for $30 \mathrm{~d}$. We removed radio-collars from kangaroo rats after $30 \mathrm{~d}$ post-release or $30 \mathrm{~d}$ out of a cage. We compared initial survivorship (to $30 \mathrm{~d}$ ) of radio-tagged Tipton kangaroo rats soft-released to those hard-released using the Fisher exact test.

\section{Population establishment}

To assess long-term survivorship, reproduction, and establishment of Tipton kangaroo rats at this site, we trapped both sides of the translocation site about 6 mo after initial work at the site had ceased and each fall (September to October) thereafter for 3 yr (2007 to 2009). In summer 2007, we set out 100 Sherman live traps on each side of the canal and trapped for $4 \mathrm{~d}$ (800 trap nights). In fall 2007 to 2009 , we set out 192 to 200 traps on each side of the canal and trapped for $3 \mathrm{~d}$ (1176 to 1200 trap nights $\mathrm{yr}^{-1}$ ). For each trapping session, we set traps in the afternoon and checked traps the next morning, starting at first light. The traps were set over the entire area where kangaroo rats had been trapped in previous years. We took an ear clip of any unmarked Tipton kangaroo rat that we captured and inserted PIT tags. To lessen time on the plots in the morning, we only determined the sex of Heermann's kangaroo rats and marked them ventrally with a felt-tipped marker pen. 


\section{Genetic analysis}

We had ear-clipped all 144 Tipton kangaroo rats that we translocated to this site in 2006. We also collected ear tissue from all unmarked Tipton kangaroo rats caught during trapping sessions. Microsatellite genotyping is used for analyzing genetic structure and pedigrees in animal populations. Microsatellite primers used in this study were characterized in banner-tailed Dipodomys spectabilis and giant D. ingens kangaroo rats by Davis et al. (2000).

We extracted genomic DNA from ear clippings using the DNeasy Tissue Kit (Qiagen) according to the manufacturer's instructions. All polymerase chain reaction (PCR) amplifications were performed in $20 \mu \mathrm{l}$ volume and contained $120 \mu \mathrm{m}$ dNTP, $0.16 \mu \mathrm{m}$ of each primer, $2 \mathrm{mM} \mathrm{MgCl}, 0.3 \mathrm{U}$ of Taq DNA polymerase, and $1 \times$ PCR buffer $(10 \mathrm{mM}$ Tris buffer, $\mathrm{pH}$ 8.8, $0.1 \%$ Triton $\mathrm{X}-100,50 \mathrm{mM} \mathrm{KCl}$, and $0.16 \mathrm{mg} \mathrm{ml}^{-1}$ bovine serum albumin). The temperature profile for the microsatellite PCR amplifications consisted of an initial denaturation step of $95^{\circ} \mathrm{C}$ for $15 \mathrm{~min}$, followed by 3 cycles of $94^{\circ} \mathrm{C}$ for $30 \mathrm{~s}, 54^{\circ} \mathrm{C}$ for $20 \mathrm{~s}$, and $72^{\circ} \mathrm{C}$ for $5 \mathrm{~s}$, followed by 33 cycles of $94^{\circ} \mathrm{C}$ for $15 \mathrm{~s}, 54^{\circ} \mathrm{C}$ for $20 \mathrm{~s}$, and $72^{\circ} \mathrm{C}$ for $1 \mathrm{~s}$. A final extension step of $72^{\circ} \mathrm{C}$ for 30 min was also added. PCR products were electrophoresed on a $1.5 \%$ agarose gel to determine size, concentration, and successful amplification. We then genotyped successful PCR products using ABI instrumentation in conjunction with the program GeneMarker V1.70.

We measured genetic diversity, including the number of alleles per locus $(A)$, observed heterozygosity $\left(H_{\mathrm{O}}\right)$, and expected heterozygosity $\left(H_{\mathrm{E}}\right)$ under HardyWeinberg assumptions (Nei 1978), using the program GENALEX V6.4 (Peakall \& Smouse 2006). We also used GENALEX to determine the degree of genetic differentiation among our predefined geographical populations with pairwise $F_{\mathrm{ST}}$ measures and analysis of molecular variance (AMOVA). In this regard, we compared the genetic structure of unmarked Tipton kangaroo rats to that of the translocated animals to determine if the 2 populations were significantly differentiated. If the unmarked animals were indeed the offspring of the translocated kangaroo rats, then we would expect that the 2 populations would not be significantly differentiated. Although a lack of genetic differentiation would not, in and of itself, indicate successful translocation and subsequent reproduction, if the 2 populations were different, then it would follow that there were undetected Tipton kangaroo rats at the translocation site when the animals were released and/or the recaptures must represent recent migrants from a neighboring, previously unknown population. As an indirect method for assessing the utility of the microsatellite loci used in this study, during spring 2010, we also collected ear clips of 20 Tipton kangaroo rats (10 male, 10 female) from another site with an established population approximately $45 \mathrm{~km}$ south of the Allensworth translocation site. We used these kangaroo rats as a control for the genetic analysis of unmarked kangaroo rats at the translocation site.

\section{RESULTS}

\section{Hard- versus soft-release}

Of the 14 kangaroo rats Dipodomys nitratoides nitratoides that we radio-collared and soft-released (caged), 1 female died within the cage and 1 animal destroyed its transmitter so we did not know its fate. Eight (5 males, 3 females) of the remaining 12 radiocollared kangaroo rats dug out of their cages before $30 \mathrm{~d}$, and 4 (2 males, 2 females) of these (50\%) survived $\geq 30 \mathrm{~d}$ following their escape (Table 1 ). Of the 4 remaining kangaroo rats that did not dig out of their cages, $3(75 \%)$ survived $\geq 30 \mathrm{~d}$ after they were freed (Table 1). Therefore, a total of 7 of 12 (58.3\%) kangaroo rats with radio-transmitters that were soft-released survived for at least $30 \mathrm{~d}$ once free from cages (Fig. 2). In contrast, 3 (2 males, 1 female) of 8 (37.5\%) kangaroo rats that were collared but were hard-released (not caged) survived $\geq 30$ d (including 1 found alive $29 \mathrm{~d}$ after release; Fig. 2). There was no significant difference in survivorship between hard- and softreleased kangaroo rats $(\mathrm{p}=0.650)$.

Although 3 of the 8 kangaroo rats that were hardreleased and collared survived at least $30 \mathrm{~d}, 5$ (3 males, 2 females) may only have survived $\leq 4 \mathrm{~d}$ (Table 1). We lost the signal for 3 animals quickly. We do not know the fate of 2 of these animals, but 1 of these kangaroo rats (No. 20) was caught in February without its radio-collar (Table 1). Also, we found 1 non-working transmitter from a caged animal (No. 14) in a burrow with signs of it being chewed. We are fairly certain of the fate of kangaroo rats for which we found collars on the ground. Either the animal had been wearing the collar for $>20 \mathrm{~d}$ or we found the collar 25 to $100 \mathrm{~m}$ from its last position after the kangaroo rat had not moved for several days. In several cases, owl pellets were found with the collar. We are fairly certain these animals were eaten by predators.

Several kangaroo rats made fairly long movements while being tracked. One caged kangaroo rat (No. 6, 
Table 1. Dipodomys nitratoides nitratoides. Sex (M: male; F: female), date of release (in 2006), fate, and survival time (ST) of translocated Tipton kangaroo rats soft- and hard-released and fitted with radio-collars at Allensworth Ecological Reserve, Tulare County, California. ST for kangaroo rats that were soft-released (caged) are days outside of the cage

\begin{tabular}{|c|c|c|c|c|c|}
\hline ID & Sex & Date & Dug out & Fate & $\mathrm{ST}(\mathrm{d})$ \\
\hline \multicolumn{6}{|c|}{ Caged (soft-release) } \\
\hline 1 & $\mathrm{~F}$ & $3 \mathrm{Dec}$ & No & Caught 29 Jan/13 Feb (no collar) & 38 \\
\hline 2 & M & $3 \mathrm{Dec}$ & $26 \mathrm{Dec}$ & Collar on ground 7 Jan & 12 \\
\hline 3 & M & $3 \mathrm{Dec}$ & 1 Jan & Caught 6 Feb & 31 \\
\hline 4 & $\mathrm{~F}$ & $3 \mathrm{Dec}$ & $7 \mathrm{Dec}$ & Re-entered cage, found dead 6 Jan & 0 \\
\hline 5 & M & $3 \mathrm{Dec}$ & No & Caught 9 Feb & 34 \\
\hline 6 & $\mathrm{~F}$ & $3 \mathrm{Dec}$ & $21 \mathrm{Dec}$ & Caught 29 Jan (no collar) & 39 \\
\hline 7 & $\mathrm{~F}$ & $8 \mathrm{Dec}$ & $21 \mathrm{Dec}$ & Collar on ground 7 Jan & 17 \\
\hline 8 & M & $8 \mathrm{Dec}$ & $13 \mathrm{Dec}$ & Caught 9 Feb (no collar) & 58 \\
\hline 9 & M & $8 \mathrm{Dec}$ & $21 \mathrm{Dec}$ & Caught 24 Jan & 34 \\
\hline 10 & M & $8 \mathrm{Dec}$ & No & Caught 6 Feb & 31 \\
\hline 11 & $\mathrm{~F}$ & $8 \mathrm{Dec}$ & No & Collar in artificial burrow 13 Feb & $?$ \\
\hline 12 & $\mathrm{~F}$ & $8 \mathrm{Dec}$ & No & Collar on ground 18 Jan & 12 \\
\hline 13 & M & $8 \mathrm{Dec}$ & $18 \mathrm{Dec}$ & Found dead near cage 29 Dec & 11 \\
\hline 14 & $\mathrm{~F}$ & $8 \mathrm{Dec}$ & $?$ & Chewed on transmitter in burrow & $?$ \\
\hline \multicolumn{6}{|c|}{ Not caged (hard-released) } \\
\hline 15 & $\mathrm{M}$ & $8 \mathrm{Dec}$ & - & Collar on ground $10 \mathrm{Dec}$ & 2 \\
\hline 16 & M & $8 \mathrm{Dec}$ & - & Caught 8 Jan & 31 \\
\hline 17 & M & $8 \mathrm{Dec}$ & - & Caught 6 Jan & 29 \\
\hline 18 & $\mathrm{~F}$ & $8 \mathrm{Dec}$ & - & Collar on ground $9 \mathrm{Dec}$ & 1 \\
\hline 19 & M & $8 \mathrm{Dec}$ & - & No signal 9 Dec & 1 \\
\hline 20 & $\mathrm{~F}$ & $8 \mathrm{Dec}$ & - & Caught 13 Feb (no collar) & 67 \\
\hline 28 & $\mathrm{~F}$ & $8 \mathrm{Dec}$ & - & No signal 12 Dec & 4 \\
\hline 59 & $\mathrm{M}$ & $10 \mathrm{Dec}$ & - & Collar on ground $11 \mathrm{Dec}$ & 1 \\
\hline
\end{tabular}

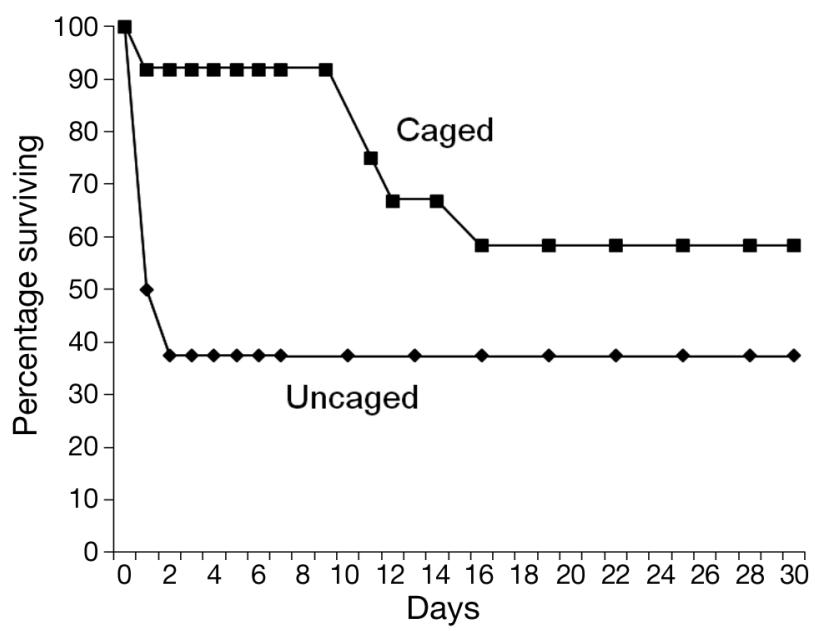

Fig. 2. Dipodomys nitratoides nitratoides. Survivorship curves of Tipton kangaroo rats fitted with radio-collars that were released into wire-mesh cages $(\mathrm{n}=14)$ or into artificial burrows without cages $(\mathrm{n}=8)$. For caged animals, survivorship was measured post-release from cages

male) moved about $40 \mathrm{~m}$ after digging out of its cage, moved several more times, but returned next to its cage after $5 \mathrm{~d}$ and was caught at this location after 30 d. Kangaroo rat No. 16 (male) was not caged, stayed in 1 burrow for $4 \mathrm{~d}$ after release, then moved about $75 \mathrm{~m}$ across the dry canal just to the edge of the north site. It was caught at this site on 8 January, and its collar was removed. Kangaroo rat No. 12 (female), which had remained in its cage for $30 \mathrm{~d}$, moved about $15 \mathrm{~m} 2 \mathrm{~d}$ after cage removal. It stayed at the new site for 3 to $5 \mathrm{~d}$, moved another $15 \mathrm{~m}$ to a previous artificial burrow, and its collar was found on the ground about $20 \mathrm{~m}$ away $3 \mathrm{~d}$ later. Most ( 6 of 7 ) collared kangaroo rats that survived $\geq 30$ d did not move $>5 \mathrm{~m}$ from where they were released.

\section{Population establishment}

We captured 16 Tipton kangaroo rats and 20 Heermann's kangaroo rats at the site in summer 2007 (Table 2). Thirteen of the 16 Tipton kangaroo rats that we captured were previously marked founder animals (although 1 was ear clipped but without a PIT tag), including 1 kangaroo rat (No. 20) that had worn a radio-collar. Of the 12 Tipton kangaroo rats that had PIT tags, 8 were soft-released and 4 were hardreleased. The 3 unclipped, untagged Tipton kangaroo rats were young-of-the-year. Minimum survivorship 8 mo after Tipton kangaroo rats were translocated to the Allensworth Ecological Reserve was $9.0 \%(13 / 144)$, with the addition of 3 young. Of the 12 Tipton kangaroo rats that we could identify by PIT tag, minimum survivorship of soft-released animals was $7.6 \%(8 / 105)$ and for hard-released kangaroo rats was $10.3 \%(4 / 39)$. These differences were not significant (Fisher exact test, $\mathrm{p}=0.735$ ).

In fall 2007, we caught 11 Tipton kangaroo rats originally released in 2006 (Table 2). During the 2008 and 2009 trapping sessions, we caught only 2 Tipton kangaroo rats ( 1 male and 1 female) which were released in 2006 (Table 2). Minimum annual estimates of survivorship of the original translocated individuals were $7.6 \%$ to fall 2007 and $1.4 \%$ survivorship to fall 2008 and fall 2009. Over the course of $3 \mathrm{yr}$, we caught 38 unmarked Tipton kangaroo rats during trapping sessions (Table 2). However, the total number of individual Tipton kangaroo rats caught during trapping subsequent to translocation remained fairly stable, but at only 15 to $23 \mathrm{yr}^{-1}$ (Fig. 3). In contrast, the number of Heermann's kangaroo rats greatly increased, with totals reaching 211 individuals in fall 2009 (Fig. 3). 
Table 2. Dipodomys nitratoides nitratoides, D. heermanni. Number of kangaroo rats (re)captured during trapping in summer 2007 and fall 2007 to 2009 at the translocation site in Allensworth Ecological Reserve, Tulare County, California. Recaptures: from season/year first marked

\begin{tabular}{|c|c|c|c|c|c|c|}
\hline \multirow{3}{*}{$\begin{array}{l}\text { Trapping } \\
\text { session }\end{array}$} & \multirow{2}{*}{\multicolumn{4}{|c|}{$\begin{array}{l}\text { Tipton kangaroo rats } \\
\text { Recaptures }\end{array}$}} & \multirow{3}{*}{$\begin{array}{c}\text { New } \\
\text { captures }\end{array}$} & \multirow{3}{*}{$\begin{array}{l}\text { Heermann's } \\
\text { kangaroo rats }\end{array}$} \\
\hline & & & & & & \\
\hline & $\begin{array}{l}\text { Fall } \\
2006\end{array}$ & $\begin{array}{l}\text { Summer } \\
2007\end{array}$ & $\begin{array}{l}\text { Fall } \\
2007\end{array}$ & $\begin{array}{l}\text { Fall } \\
2008\end{array}$ & & \\
\hline Summer 2007 & 13 & - & - & - & 3 & 20 \\
\hline Fall 2007 & 11 & 2 & - & - & 10 & 39 \\
\hline Fall 2008 & 2 & 1 & 1 & - & 16 & 167 \\
\hline Fall 2009 & 2 & 1 & - & 3 & 9 & 211 \\
\hline
\end{tabular}

\section{Genetic analysis}

Initially, we evaluated all of the microsatellite loci characterized by Davis et al. (2000) for amplification success from the kangaroo rats that were targeted for translocation. Of these, only DS1 and DS30, both of which comprise 'GT' dinucleotide repeat motifs, amplified with consistency. This is not entirely surprising because these loci were characterized in species of Dipodomys different from those reported on here, and these were the only loci that have been shown to amplify across different rodent genera (e.g. Dipodomys and Chaetodipus; Davis et al. 2000). The size of DS1, including primers, ranged from 191 to $256 \mathrm{bp}$, and the size of DS30, including primers, ranged from 225 to $312 \mathrm{bp}$ (Table 3). We attempted PCR amplification of DS1 and DS30 for all samples. Of those samples that could be amplified for DS1, 108 were from the original translocated population and 26 represented unmarked individuals (Table 3). The failure of some PCR amplifications may be due to primer mismatch at the critical 3' end and/or inadequate genomic DNA extraction. Despite these fail- ures, we were still able to obtain sufficient amplification of both alleles from 114 kangaroo rats across the 3 populations analyzed in this study, including 79 from the translocation group, 24 from the unmarked group, and 18 from the Buttonwillow site.

The DS1 locus was polymorphic for both groups, with 7 alleles recognized in the translocated kangaroo rats and 6 alleles recognized in the unmarked individuals. For the unmarked group, there were no alleles that were not also represented in the translocated

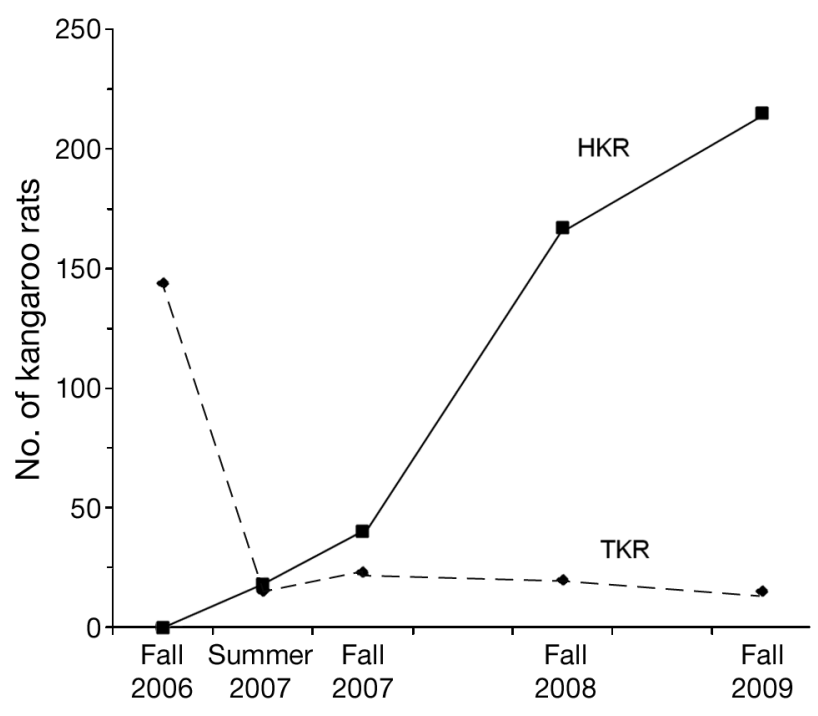

Fig. 3. Dipodomys nitratoides nitratoides, D. heermanni. Number of individual Tipton kangaroo rats $D$. n. nitratoides (TKR) released (December 2006), and number of Tipton kangaroo rats and Heermann's kangaroo rats D. heermanni (HKR) caught during trapping sessions at the Allensworth Ecological Reserve, Tulare County, California, from 2007 to 2009

Table 3. Dipodomys nitratoides nitratoides. Microsatellite characteristics of locus DS1 and DS30 in translocated and unmarked Tipton kangaroo rats at the Allensworth Ecological Reserve, Tulare County, California, and in Tipton kangaroo rats from Buttonwillow, Kern County, California, approximately $45 \mathrm{~km}$ south of the translocation site

\begin{tabular}{|c|c|c|c|c|c|c|c|c|c|c|c|c|c|}
\hline \multirow{2}{*}{$\begin{array}{l}\text { Group } \\
\text { DS1 }\end{array}$} & \multirow[t]{2}{*}{$\mathrm{n}$} & \multirow{2}{*}{$\begin{array}{l}\text { Size range }(\mathrm{bp}) / \\
\text { no. of alleles }\end{array}$} & \multicolumn{11}{|c|}{ — Allele size (bp) } \\
\hline & & & 187 & 191 & 197 & 203 & 209 & 219 & 223 & 227 & 231 & 241 & 256 \\
\hline Translocated & 108 & $191-256 / 7$ & 0 & 0.07 & 0.25 & 0.05 & 0 & 0.21 & 0.32 & 0.09 & 0 & 0 & 0.01 \\
\hline Unmarked & 26 & $191-227 / 6$ & 0 & 0.06 & 0.28 & 0.04 & 0 & 0.19 & 0.38 & 0.05 & 0 & 0 & 0 \\
\hline Buttonwillow & 20 & $187-241 / 8$ & 0.10 & 0 & 0.10 & 0.05 & 0.08 & 0.17 & 0.35 & 0 & 0.13 & 0.02 & 0 \\
\hline DS30 & & & 225 & 233 & 240 & 247 & 281 & 294 & 300 & 312 & 318 & 324 & 330 \\
\hline Translocated & 72 & $225-312 / 6$ & 0.06 & 0.61 & 0 & 0 & 0.03 & 0.08 & 0.11 & 0.11 & 0 & 0 & 0 \\
\hline Unmarked & 24 & $233-312 / 5$ & 0 & 0.72 & 0 & 0 & 0.065 & 0.125 & 0 & 0.09 & 0 & 0 & 0 \\
\hline Buttonwillow & 18 & $233-330 / 8$ & 0 & 0.11 & 0.11 & 0.03 & 0 & 0 & 0.25 & 0.30 & 0.03 & 0.11 & 0.06 \\
\hline
\end{tabular}


group. Alleles '197' and '223' were the most frequent, representing 25 and $28 \%$ for Allele '197' and 32 and $38 \%$ for Allele ' 223 ' of the total frequency in the translocated and unmarked groups, respectively (Table 3). The DS30 locus was polymorphic for both groups with 6 alleles recognized in the translocated kangaroo rats and 5 alleles recognized in the unmarked individuals. Allele '233' was, by far, the most frequent allele, representing 61 and $72 \%$ of the total frequency in the translocated and unmarked groups, respectively (Table 3 ).

We also amplified and genotyped the DS1 and DS30 loci from 20 kangaroo rats collected from the Buttonwillow site. For this group we detected 8 alleles each for DS1 and DS30. For DS1, Allele '223' was the most frequent (35\%). A qualitative comparison of DS1 allele representation across groups indicated that there were 4 alleles 'unique' to the Buttonwillow group and 4 alleles 'unique' to the kangaroo rats associated with the translocation site. In contrast, there were only 3 alleles $(233,300,312)$ that were common between Buttonwillow and the translocation sites for DS30.

Observed heterozygosities ranged from 0.42 to 0.72 , and expected heterozygosities ranged from 0.47 to 0.80 for both loci across the 3 groups analyzed (Table 4). Fixation indices were much lower for the DS30 locus for Tipton kangaroo rats from Allensworth than those from the Buttonwillow site, although they were similar across sites for the DS1 locus (Table 4). An AMOVA, based on 10000 permutations of the distance matrix for calculation of $\Phi_{\mathrm{ST}}$, revealed significant heterogeneity among the 3 populations $\left(\Phi_{\mathrm{ST}}=0.106, \mathrm{p}<0.01\right.$; Table 5$)$. Pairwise population comparisons based on $F_{\mathrm{ST}}, \Phi_{\mathrm{ST}}$, and Nei's genetic distance indicated that the Buttonwillow group was significantly different from the translocation and unmarked groups; however, the translocation and unmarked groups were not significantly different from each other (Table 5).

\section{DISCUSSION}

Our results indicate that the Tipton kangaroo rats Dipodomys nitratoides nitratoides translocated from a donor site near Lamont in Kern County to the Allensworth Ecological Reserve had become established and were successfully reproducing, although
Table 4. Dipodomys nitratoides nitratoides. Effective number of alleles $\left(N_{\mathrm{e}}\right)$, information index $(I)$, observed heterozygosity $\left(H_{\mathrm{O}}\right)$, expected heterozygosity $\left(H_{\mathrm{E}}\right)$, and fixation $(F)$ indices for translocated (TRANS) and unmarked (UNMKD) Tipton kangaroo rats at the Allensworth Ecological Reserve, Tulare County, California, and in Tipton kangaroo rats from Buttonwillow, Kern County, California, approximately $45 \mathrm{~km}$ south of the translocation site (BUTTN). $F_{\text {IS }}$ : standard genetic variation within populations; $F_{\mathrm{IT}}$ : to partition genetic variation; $F_{\mathrm{ST}}$ : standard genetic variation between populations

\begin{tabular}{|lcccccc|}
\hline \multirow{2}{*}{ Group } & Locus & $N_{\mathrm{e}}$ & $I$ & $H_{\mathrm{O}}$ & $H_{\mathrm{E}}$ & $F$ \\
\hline TRANS & DS1 & 4.7 & 1.6 & 0.56 & 0.79 & 0.31 \\
& DS30 & 2.2 & 1.2 & 0.72 & 0.55 & 0.09 \\
UNMKD & DS1 & 3.8 & 1.4 & 0.54 & 0.74 & 0.27 \\
& DS30 & 1.8 & 0.9 & 0.42 & 0.47 & 0.10 \\
BUTTN & DS1 & 4.9 & 1.8 & 0.56 & 0.80 & 0.33 \\
& DS30 & 4.9 & 1.7 & 0.72 & 0.80 & 0.36 \\
Genetic variation & $F_{\mathrm{IS}}$ & $F_{\mathrm{IT}}$ & $F_{\mathrm{ST}}$ & & \\
\hline \multirow{2}{*}{ All } & DS1 & 0.301 & 0.320 & 0.028 & & \\
& DS30 & 0.178 & 0.296 & 0.144 & & \\
& Mean & 0.239 & 0.308 & 0.068 & & \\
\hline
\end{tabular}

the population was not robust. This contrasts with past translocations of Tipton kangaroo rats that have either failed or the outcome was undetermined (Germano 2001, 2010). This establishment does not seem to be due to caging kangaroo rats because there was no difference in $30 \mathrm{~d}$ and 6 mo survivorship between soft- and hard-released animals. Successful establishment may have been because we moved large numbers of Tipton kangaroo rats. Although we suspect that predators did kill some translocated kangaroo rats within the first month of their release, mov-

Table 5. Dipodomys nitratoides nitratoides. Population comparisons, including pairwise $F_{\mathrm{ST}}, \Phi_{\mathrm{ST}}$, Nei's genetic distance, and the results of an analysis of molecular variance (AMOVA) for translocated (TRANS) and unmarked (UNMKD) Tipton kangaroo rats at the Allensworth Ecological Reserve, Tulare County, California, and in Tipton kangaroo rats from Buttonwillow, Kern County, California, approximately $45 \mathrm{~km}$ south of the translocation site (BUTTN). * Significant difference at $\mathrm{p}<0.01$

\begin{tabular}{|c|c|c|c|c|c|c|}
\hline & \multicolumn{2}{|c|}{ Pairwise $F_{\mathrm{ST}}$} & \multicolumn{2}{|c|}{ Pairwise $\Phi_{\mathrm{ST}}$} & \multicolumn{2}{|c|}{$\begin{array}{l}\text { Nei's pairwise } \\
\text { distance }\end{array}$} \\
\hline TRANS vs. UNMKD & \multicolumn{2}{|c|}{0.009} & \multicolumn{2}{|c|}{0.000} & \multicolumn{2}{|c|}{0.025} \\
\hline TRANS vs. BUTTN & \multicolumn{2}{|c|}{$0.075^{*}$} & \multicolumn{2}{|c|}{$0.179^{*}$} & \multicolumn{2}{|c|}{0.554} \\
\hline UNMKD vs. BUTTN & \multicolumn{2}{|c|}{$0.099^{*}$} & \multicolumn{2}{|c|}{$0.232^{*}$} & \multicolumn{2}{|c|}{0.652} \\
\hline AMOVA & df & SS & MS & $\%$ variation & $\Phi$ & $\mathrm{p}$ \\
\hline Among populations & 2 & 16.70 & 8.35 & 0.11 & & \\
\hline Within populations & 118 & 211.53 & 1.80 & 0.89 & 0.106 & 0.00 \\
\hline Total & 120 & 228.23 & 10.15 & & & \\
\hline
\end{tabular}


ing 144 Tipton kangaroo rats to the site may have provided a population base large enough to absorb predation losses and allow early survivors to become established. Also, the translocation site was devoid, or nearly so, of a resident population of kangaroo rats, although this area had supported Tipton kangaroo rats in the past (US Fish and Wildlife Service 1998, California Department of Fish and Game unpubl. report). However, sometimes even large numbers of translocated animals may not be sufficient. In 1992, O'Farrell (unpubl. report; as cited in Shier \& Swaisgood 2012) translocated 599 Stephens' kangaroo rats, but found no surviving animals 11 mo following their release.

Although adult survivorship was fairly low, it was not too dissimilar to natural survivorship found for the closely related short-nosed kangaroo rat Dipodomys nitratoides brevinasus in the Lokern Natural Area. We found a mean annual survivorship of only $17.6 \%$ over a 10 yr period at the Lokern site (D. J. Germano et al. unpubl. data). We note also that the estimates of $9.0 \%$ survivorship for the first $8 \mathrm{mo}$ and $7.6 \%$ for the first year are minima because we may not have caught all the kangaroo rats still surviving at the site, and some animals may have moved far enough from where we trapped so as not to be detected.

The apparent failure of the Tipton kangaroo rat population to grow may have been due to the rapid increase we observed among Heermann's kangaroo rats at the translocation site. This species may competitively suppress Tipton kangaroo rats (Tennant \& Germano 2013). Only 1 Heermann's kangaroo rat was caught at the release site about 3 mo before we released Tipton kangaroo rats in December 2006. We caught a few Heermann's kangaroo rats during summer trapping in 2007, but their numbers steadily increased. By 2008, Heermann's kangaroo rats occurred across virtually the whole trapping grid on both sides of the site. The population of Tipton kangaroo rats at the translocation site was steady, but not increasing. In contrast, numbers of Tipton kangaroo rats at a permanent study plot at the Buttonwillow Ecological Reserve off 7th Standard Road $(45 \mathrm{~km}$ south of Allensworth) in Kern County increased markedly from 2006 to 2009 (D. J. Germano unpubl. data), and large numbers of Tipton kangaroo rats were caught in 2008 and 2009 at the Semitropic Preserve (35 km southwest of Allensworth) in Kern County managed by the Center for Natural Lands Management (G. Warrick pers. comm.).

Similar short-term results after translocation have been found in other studies of kangaroo rats. O'Far- rell (1999) translocated 15 San Bernardino kangaroo rats Dipodomys merriami parvus from one area to a reclaimed mine site. Initial trapping at the receiver site before translocation revealed 3 San Bernardino kangaroo rats and 23 of the larger Dulzura kangaroo rat $D$. simulans occurred there. San Bernardino kangaroo rats translocated to the receiver site were hardreleased within $5 \mathrm{~d}$ of capture and were not even released into artificial burrows. However, O'Farrell (1999) trapped the receiver site 3 mo later and caught 6 translocated kangaroo rats (40\% survivorship). In 1989, 60 giant kangaroo rats in 2 groups of 30 were moved to new sites on the Carrizo Plain, San Luis Obsipo County (Williams et al. 1993). One group of 30 kangaroo rats was translocated to artificial burrows in a recently fallowed plowed field; all rats were dead within 6 mo. Another group of 30 animals that were moved to vacant natural habitat survived for several years, and the population grew exponentially until it crashed when the climate became wet in the mid-1990s (Endangered Species Recovery Program unpubl. data). In another study, 12 Tipton kangaroo rats were translocated to a location approximately $2 \mathrm{~km}$ from a project site (Germano 2001). Based on 6 mo of trapping, 3 translocated animals (25\%) were known to have survived, but the fate of the other 9 kangaroo rats was undetermined. Finally, 4 radiocollared Tipton kangaroo rats that were hardreleased, but were released into artificial burrows, survived only a few days after translocation (Germano 2010).

In contrast to these translocation studies, Shier \& Swaisgood (2012) successfully translocated Stephen's kangaroo rats using a combination of softrelease methods and maintaining the social structure of animals from the donor site. Although the Stephen's kangaroo rat is a solitary species, they found that kangaroo rats translocated with neighbors traveled shorter distances before establishing territories, had higher survival rates, and had significantly higher reproductive success than the group translocated without regard to neighbor status. Although many species of kangaroo rats are solitary, including the Tipton kangaroo rat, maintaining neighbor spatial relationships when translocating groups may be very important to translocation success.

Predation is one of the main detriments to successful translocation of vertebrates (Wolf et al. 1996, Fischer \& Lindenmayer 2000). This is often the case with naive animals that are captive-raised, because they do not develop a fear of predators, and also with translocated wild individuals because they are unfamiliar with the release site. A study of sibling voles 
Microtus rossiaemeridionalis showed that death by predation is highest within the first $3 \mathrm{~d}$ after release, before the animals move from the release site (Banks et al. 2002). Kangaroo rats are preyed upon by a variety of species, including snakes, owls, hawks, weasels, and foxes (Grinnell 1932, Culbertson 1946, Hawbecker 1951, Daly et al. 1990). Snakes, weasels, and foxes may be attracted to newly constructed burrows, and these burrows may not be intricate enough to allow kangaroo rats to escape predators that can enter burrows. Alternatively, if kangaroo rats immediately leave artificial burrows after release, their risk of predation may be increased because they would not know the site well enough to find escape burrows. We did not find statistical support for the use of cages as a means of deterring predation after initial release. However, we had small sample sizes, and further studies should be conducted to determine if the additional labor and expense of caging kangaroo rats is justified, especially if caging is combined with maintaining neighbor relationships from donor sites.

The genetic data presented here are consistent with what we would expect if the translocated Tipton kangaroo rats were successfully reproducing. We cannot discount the possibility that there was an undetected small population of Tipton kangaroo rats in the vicinity of our study site that contributed offspring, but we do not believe this is likely. The natural lands that make up the reserve were covered with dense grasses, except the site we chose, and no Tipton kangaroo rats were caught at this site 3 mo prior to our translocation. Otherwise, the reserve was surrounded by irrigated agriculture. Also, it seems unlikely, although not impossible, that kangaroo rats resident at the translocation site would have the exact genetic makeup for the loci we characterized for kangaroo rats from the donor site $85 \mathrm{~km}$ away, while we found differences in genetic makeup for a population of kangaroo rats $45 \mathrm{~km}$ away. While we believe that the results of the pairwise population comparisons are compelling, our results are based on only 2 microsatellite loci originally characterized in other species of Dipodomys. Additional loci, those specifically characterized for $D$. nitratoides nitratoides, would have certainly provided more robust evidence of successful reproduction. Indeed, a comprehensive population genetic study on Tipton kangaroo rats throughout their range would be a valuable resource for future conservation efforts.

Despite evidence of successful reestablishment of Tipton kangaroo rats at the Allensworth Ecological Reserve, the precarious nature of the population highlights the need for effective management of the site. Of particular importance is the need to keep the herbaceous cover at a low stature. Most of the San Joaquin Valley is desert (Germano et al. 2011), with non-native grasses invading the area about 2 centuries ago. Dense grass and forb cover may hinder the movements of kangaroo rats (Bartholomew \& Caswell 1951, O'Farrell \& Uptain 1987) and can lead to their extirpation at a site (Germano et al. 2001). Also, it is possible that dense herbaceous cover interferes with foraging (Brock \& Kelt 2004), because heteromyid rodents primarily harvest seeds off of the soil surface (Price \& Joyner 1997) by scratch digging. The area needs to be managed by selective grazing or other means during high cover years to keep the height of herbaceous plants low. If this is not done, it is likely that the population of Tipton kangaroo rats we have reestablished at the reserve will be lost.

Short term, it may also be beneficial to Tipton kangaroo rats to decrease the numbers of the rapidly expanding Heermann's kangaroo rats. A recent study at the Allensworth translocation site found that numbers of Tipton kangaroo rats increased dramatically in $1 \mathrm{yr}$ when Heermann's kangaroo rats were removed from an enclosure established on the north side in the fall of 2009 (Tennant \& Germano 2013). Behavioral observations showed that Tipton kangaroo rats avoided the larger Heermann's kangaroo rats in the enclosure. After Heermann's kangaroo rats were removed from the exclusion plot, numbers of Tipton kangaroo rats increased $500 \%$ in $12 \mathrm{mo}$, whereas numbers at a control site with Heermann's kangaroo rats were low and showed a downward trend. Selective trapping to remove Heermann's kangaroo rats may be necessary until Tipton kangaroo rat numbers have increased to a much higher level than currently seen at the site. Ultimately, Tipton kangaroo rats could spread to the east in the reserve if the area is kept relatively free of thick ground cover.

Although translocation is not a method to be advocated over habitat protection, continued legal development in the range of a threatened species anywhere in the world demands finding ways to save displaced populations. Appropriate methods of translocating animals need to be determined. In the case of kangaroo rats in the San Joaquin Valley, additional research is needed on optimal strategies for translocating individuals and establishing new populations. Habitat availability in this region is already extremely limited (US Fish and Wildlife Service 1998) and continues to decline. However, opportunities to establish new populations may 
become available either on lands where kangaroo rats have become extirpated or on former agricultural lands that are currently being purchased and restored for conservation purposes (E. Tennant pers. comm.). Also, there will continue to be a need to translocate animals from sites approved for development. Future research should address: the value of caging kangaroo rats at sites prior to release, moving animals in neighbor groups, the relative merit of short-term removal of competing species, and appropriate habitat management strategies.

Acknowledgements. We thank Jesse Wild of the US Fish and Wildlife Service and Steve Juarez of the California Department of Fish and Game for guiding this study from the regulatory end. We also thank Steve Juarez for providing employees to help with trapping, cage construction, and installation. Marcia Wolfe led the removal trapping of kangaroo rats from the Lamont site and was assisted by Ellen Cypher, Shari Heittkotter, Laura Peterson-Diaz, Erin Tennant, Linda Connolly, Alyssa Eisner, and Katrina Esch. We were assisted in burrow construction and cage placement by Amy Kuritsubo, Denis Kearns, Noah Kearns, Erin Tennant, Scott Yoo, and Mike Carter. In 2007, we were helped by students from the Vertebrate Diversity class at California State University, Bakersfield; in 2008 by personnel of the Bureau of Land Management and Erin Tennant; and in 2009 by Erin Tennant, Susan Hult, Rochelle Germano, Hui Wang, Tory Reedy, Shelly Buranek, and Sherri Heitkotter. Partial funding for this study was given to the senior author by the Endangered Species Recovery Program. Fig. 1 was created by Larry Vredenburgh. Work was done under Federal Permit TE49872-5, and California Collecting Permit 801259-05 and a Memorandum of Understanding dated 8 February 2006.

\section{LITERATURE CITED}

Banks PB, Norrdahl K, Korpimaki E (2002) Mobility decisions and the predation risks of reintroduction. Biol Conserv 103:133-138

Bartholomew GA Jr, Caswell HH Jr (1951) Locomotion in kangaroo rats and its adaptive significance. J Mammal 32:155-169

Bright P, Morris P (1994) Animal translocation for conservation: performance of dormice in relation to release methods, origin and season. J Appl Ecol 31:699-708

Brock RE, Kelt DA (2004) Keystone effects of the endangered Stephens' kangaroo rat (Dipodomys stephensi). Biol Conserv 116:131-139

Culbertson AE (1946) Observations on the natural history of the Fresno kangaroo rat. J Mammal 27:189-203

Daly M, Wilson M, Behrends PR, Jacobs LF (1990) Characteristics of kangaroo rats, Dipodomys merriami, associated with differential predation risk. Anim Behav 40: 380-389

Davis C, Keane B, Swanson B, Loew S, Waser PM, Strobeck X, Fleischers C (2000) Characterization of microsatellite loci in bannertailed and giant kangaroo rats, Dipodomys spectabilis and Dipodomys ingens. Mol Ecol Notes 9: 629-644
Ellis DH, Gee GF, Hereford SG, Olsen GH and others (2000) Post-release survival of hand-reared and parent-reared Mississippi sandhill cranes. Condor 102:104-112

> Fischer J, Lindenmayer DB (2000) An assessment of published results of animal relocations. Biol Conserv 96:1-11

Gatti RC (1981) A comparison of two hand-reared mallard release methods. Wildl Soc Bull 9:37-43

Germano DJ (2001) Assessing translocation and reintroduction as mitigation tools for Tipton kangaroo rats (Dipodomys nitratoides nitratoides). Trans West Sec Wildl Soc 37:71-76

Germano DJ (2010) Survivorship of translocated kangaroo rats in the San Joaquin Valley of California. Calif Fish Game 96:82-89

Germano DJ, Rhodehamel WM (1995) Characteristics of kangaroo rat burrows in fallow fields of the southern San Joaquin Valley. Trans West Sec Wildl Soc 31:40-44

Germano DJ, Rathbun GB, Saslaw LR (2001) Managing exotic grasses and conserving declining species. Wildl Soc Bull 29:551-559

Germano DJ, Rathbun GB, Saslaw LR, Cypher BL, Cypher EA, Vredenburgh LM (2011) The San Joaquin Desert of California: ecologically misunderstood and overlooked. Nat Areas J 31:138-147

Griffith B, Scott JM, Carpenter JW, Reed C (1989) Translocation as a species conservation tool: status and strategy. Science 245:477-480

> Grinnell J (1932) Habitat relations of the giant kangaroo rat. J Mammal 13:305-320

> Hardman B, Moro D (2006) Optimising reintroduction success by delayed dispersal: Is the release protocol important for hare-wallabies? Biol Conserv 128:403-411

Harker MB, Rathbun GB, Langtimm CA (1999) Beadedchain collars: a new method to radiotag kangaroo rats for short-term studies. Wildl Soc Bull 27:314-317

Hawbecker AC (1951) Small mammal relationships in an ephedra community. J Mammal 32:50-61

Holland RF (1986) Preliminary descriptions of the terrestrial natural communities of California. State of California, The Resources Agency, California Department of Fish and Game, Nongame Heritage Program, Sacramento, CA

Holler NR, Mason DW, Dawson RM, Simons T, Wooten MC (1989) Reestablishment of the Perdido Key beach mouse (Peromyscus polionotus trissyllepsis) on Gulf Islands National Seashore. Conserv Biol 3:397-404

Mitchell AM, Wellicome TI, Brodie D, Cheng KM (2011) Captive-reared burrowing owls show higher site-affinity, survival, and reproductive performance when reintroduced using a soft-release. Biol Conserv 144:1382-1391

Nei M (1978) Estimation of average heterozygosity and genetic distance from a small sample of individuals. Genetics 155:583-590

O'Farrell MJ (1999) Translocation of the endangered San Bernardino kangaroo rat. Trans West Sec Wildl Soc 35: $10-14$

O'Farrell MJ, Uptain CE (1987) Distribution and aspects of the natural history of Stephens' kangaroo rat (Dipodomys stephensi) on the Warner Ranch, San Diego Co., California. Wasmann J Biol 45:34-48

> Peakall R, Smouse PE (2006) GENALEX 6: genetic analysis in Excel. Population genetic software for teaching and research. Mol Ecol Notes 6:288-295

Price MV, Joyner JW (1997) What resources are available to desert granivores: Seed rain or soil seed bank? Ecology 78:764-773 
Shier DM, Swaisgood RR (2012) Fitness costs in neighborhood disruption in translocations of a solitary mammal. Conserv Biol 26:116-123

Single JR, Germano DJ, Wolfe MH (1996) Decline of kangaroo rats during a wet winter in the southern San Joaquin Valley, California. Trans West Sec Wildl Soc 32:34-41

Tennant EN, Germano DJ (2013) A case study of competitive interactions between Tipton (Dipodomys nitratoides nitratoides) and Heermann's (D. heermannii) kangaroo rats in the San Joaquin Valley of California. Southwestern Nat (in press)

US Fish and Wildlife Service (1998) recovery plan for the upland species of the San Joaquin Valley, California. Region 1. Portland, Oregon. Available at: http://esrp. csustan.edu/publications/recoveryplan.php (accessed 15 May 2011)

Uptain CE, Williams DF, Kelley PA, Hamilton LP, Potter MC (1999) The status of Tipton kangaroo rats and the potential for their recovery. Trans West Sec Wildl Soc 35:1-9

Wanless RM, Cunningham J, Hockey PAR, Wanless J, White RW, Wiseman R (2002) The success of a soft-release re-

Editorial responsibility: Wayne Linklater, Wellington, New Zealand introduction of the flightless Aldabra rail (Dryolimnas [cuvieri] aldabranus) on Aldabra Atoll, Seychelles. Biol Conserv 107:203-210

Williams DF, Germano DJ (1992) Recovery of endangered kangaroo rats in the San Joaquin Valley, California. Trans West Sec Wildl Soc 28:93-106

Williams DF, Germano DJ, Tordoff W III (1993) Population studies on endangered kangaroo rats and blunt-nosed leopard lizards in the Carrizo Plain Natural Area, California. Nongame Bird and Mammal Section Report 93-01, California Department of Fish and Game, Sacramento, CA

Williams DF, Tordoff W III, Germano DJ (1997) Evaluation of methods for permanently marking kangaroo rats (Dipodomys: Heteromyidae). In: Yates TL, Gannon WL, Wilson DE (eds) Life among the muses: papers in honor of James S. Findley. Spec Publ No. 3, Museum of Southwestern Biology, Albuquerque, NM

Wolf CM, Griffith B, Reed C, Temple SA (1996) Avian and mammalian translocations: update and reanalysis of 1987 survey data. Conserv Biol 10:1142-1154

Submitted: March 29, 2012; Accepted: October 10, 2012

Proofs received from author(s): January 4, 2013 